Research Article

\section{Effect of Nutritional Composition and Glycemic Index on Selected Varieties of Rice, Millets and Legumes}

\author{
Dr. Kavitha G Singh*, Shriya Kasera, Priyadarshini K V \\ Mount Carmel College (Autonomous), 58, Palace Rd, Ashok Layout, Vasanth Nagar, Bengaluru, Karnataka 560052, India. \\ *Corresponding author's E-mail: kavi182@yahoo.com
}

Received: 24-06-2021; Revised: 19-08-2021; Accepted: 28-08-2021; Published on: 15-09-2021.

\begin{abstract}
Diabetes mellitus is a disease that is increasing globally and is a group of metabolic disorder, characterized by polyuria, polyphagia and polydypsia. By maintaining glycemic index levels in individuals diet aids in prevention of diabetes. Rice, millets and legumes are considered to be one of the staple food and play a vital role in human diet. In our study the glycemic index of varieties of rice, millets and legumes were determined in-vitro. Consumption of foods with high glycemic index is hypothesized to contribute to insulin resistance, which is associated with increased risk of diabetes mellitus, obesity and cardiovascular disease. It was seen that the legumes possess low glycemic index with comparison to rice and millets. Hence, it can be concluded that legumes are particularly good for preventing and managing diabetes.
\end{abstract}

Keywords: Diabetes mellitus, glycemic index, hydrolysis index, hypoglycemia.

QUICK RESPONSE CODE $\rightarrow$

DOI:

10.47583/ijpsrr.2021.v70i01.019

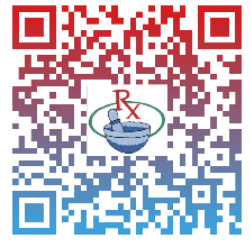

DOI link: http://dx.doi.org/10.47583/ijpsrr.2021.v70i01.019

\section{INTRODUCTION}

$\mathrm{D}$ iabetes mellitus (DM), can also be called as diabetes, is a group of metabolic disorders in which there are high blood sugar levels over a prolonged period. Symptoms of high blood sugar include frequent urination, increased thirst, and increased hunger. If left untreated, diabetes can cause many complications. Serious long-term complications include heart disease, stroke, chronic kidney failure, and damage to the eyes.

Hypoglycemia, also known as low blood sugar, is when blood sugar decreases to below normal levels. Recognition of hypoglycemia risk factors, blood glucose monitoring, selection of appropriate regimens, education programs for healthcare professionals and patients with diabetes are the major issues to maintain good glycemic control, minimize risk of hypoglycemia, and prevent longterm complications.

By maintaining the glycemic index levels in individual's diet aid in prevention of diabetes. Glycemic index (GI) is a number associated with particular type of food that indicates the foods effect on a person's blood glucose or sugar level. Glycemic index of the test food can be predicted by the hydrolysis index $(\mathrm{HI})$ of a carbohydrate based test food with that of reference foods ${ }^{1}$. Since the availability of low GI (glycemic index) foods are very restricted, more number of products with low $\mathrm{Gl}$ will be required for a balanced low GI diet ${ }^{2}$. These benefits are of great importance in the nutritive treatment of diabetes mellitus, it improves glycemic control. Legumes have a very low glycemic index ${ }^{3}$ which has been ascribed with various other factors such as tannins ${ }^{4}$ and phytic acid ${ }^{5}$. Nutrition is a fundamental requirement in everyday diet and it takes part in progress of health \& mental status and in turn increases the labor productivity of population. But in reality, hunger and malnutrition are major concerns in most places because of more population, shortage of fertile land and more prices of food ${ }^{6}$. Various nutritional factors are involved which effect the augmenting of both type of diabetes, for example, consume vegetables every day at the time of pregnancy decreased the complications of a child's evolving type 1 diabetes ${ }^{7}$.

\section{Brown rice and white rice}

Rice (Oryza sativa) is one of the most essential food crop and half of the world's population consume it. Rice is a vital cereal crop taken as a primary food. But in comparison with brown and white rice, brown rice has many nutritive values that is it is rich in fiber, antioxidant, minerals and vitamins. Rice is classified as white or brown rice based on their nutritive value and quality after harvesting processes. White rice or polished rice which contain higher quantity of starch could be obtained by various mechanisms or processes that includes milling and hulling ${ }^{8}$. To attain nutritional stability consumption of less milled rice is highly recommended. Brown rice is considered to have great amounts of many bio-active compounds, proteins, fiber content, trace elements, and lipids etc. Because of the low glycemic index of brown rice some of the population consume it which can be helpful in reducing the risk of diabetes (type 2). 


\section{Finger millet and pearl millet}

Finger millet (Eleusine coracana) it is a clustered, robust and long grass which is grown annually. The inflorescence looks like spikes or fingers which resembles a fist, which is why it is called as finger millet $^{9}$ the spikes get further divided into spikelet, containing 4 to 7 seeds $^{10}$. It is one of the main food ingredients for staple diet in Karnataka, India and is highly rich in carbohydrate and reported to be in range of 72 to $79.5 \%{ }^{11}$. It is a very good alternative for gluten sensitive people as it does not contain gluten. Health benefits such as timely nutrient absorption, reducing of blood lipids, prevention against colon cancer, good digestion and excretion can be observed in finger millets consumption. Pearl millet (Pennisetum glaucum), it has traditionally been important in arid and sub- tropical regions. It is most widely used millet. The starch content is between 62.8 to $70.5 \%$ ). It also contains soluble sugar $1.2 \%$ to $2.6 \%$ and amylose 18.3 to $24.6 \%{ }^{12}$. Some low value of starch and amylose can be found in some of the Indian pearl millet varieties. Is also present which is occupied by $66 \%$ sucrose and $28 \%$ raffinose other sugars are stachyose, glucose and fructose.

Recently millets are receiving spotlight in combating diabetes as a dietary option ${ }^{13}$. Compared to other cereal crops such as wheat and maize, millets are high in nutritional content, gluten free, and have low glycemic index ${ }^{14}$. They are known to have high amount of mineral ${ }^{15}$ and leucine ${ }^{16}$ content that are positively attributed toward healthy diet for diabetics.

\section{Kidney beans and soya beans}

Glycine max, commonly known as soybean in North America or soya bean, is a species of legume native to East Asia, widely grown for its edible bean which has numerous uses. Soya beans are a globally important crop, providing oil and protein.

Kidney beans (Phaseolus vulgaris) also called as French bean or common bean, red kidney beans. It is a very good source of potassium and have more amount of carbohydrate. Consumption of raw legumes leads to acute complications like nausea, vomiting and diarrhea and there is no equivocal proof for chronic effects. Hence for human consumption the legumes are processed by various methods. It is often considered that soaking improves the quality of beans by reducing certain antinutritional factors which will be present in the beans. They provide the only high protein component and over 10 million tonnes are consumed annually ${ }^{17}$.

\section{MATERIALS AND METHODS}

\section{Sample preparation}

The raw samples like white rice, brown rice, finger millet, pearl millet, kidney beans and soybeans were bought from the local market and prepared accordingly for determining proximate analysis by using AOAC method.

\section{Proximate analysis}

Ash, moisture, fibre and fat of the samples were determined by a histogram graph for the singleton values obtained. Protein and carbohydrate were also determined by histogram for the values obtained. Glycemic index was obtained by hydrolysis index method.

\section{Estimation of Ash Content}

Dry and clean crucibles were weighed accurately. Approximately $2 \mathrm{~g}$ of the sample was taken in a crucible and weighed accurately. The crucibles were dried in the hot air oven at $600^{\circ} \mathrm{C}$ for 1 hour till charred. The sample was then cooled and weighed accurately. From the weights, the ash content was calculated as $\%^{18}$.

$$
\text { Ash content }=\frac{(w 2-w 3)}{(w 2-w 1)} \times 100
$$

\section{Estimation of Moisture Content}

An empty clean and dry china dish was weighed accurately. Approximately $2 \mathrm{~g}$ of the sample (finely ground powder) was added to the china dish and weighed accurately. This sample was dried at $110^{*} \mathrm{C}$ in the hot air oven. This was repeated till the constant weight was obtained. From the weights, the moisture content was calculated as $\%^{18}$.

$$
\text { Moisture content } \%=\frac{(w 2-w 3)}{(w 2-w 1)} \times 100
$$

\section{Estimation of Fiber Content}

In a crucible $1 \mathrm{~g}$ of the sample was dissolved in $50 \mathrm{ml}$ of $1.25 \%$ sulphuric acid. This solution was kept on a hot plate at $70^{*} \mathrm{C}$ for $15 \mathrm{~min}$, filtered and to the sediment $50 \mathrm{ml}$ of sodium hydroxide was added. This solution was again kept on a hot plate for $70^{*} \mathrm{C}$ for $15 \mathrm{mins}$. Then again filtered it with ethanol. Then fiber content was estimated as grams $^{18}$.

$$
\text { Percentage crude fiber }=\frac{w 1-w 2}{w 1} \times 100
$$

\section{Estimation of Total Protein By Lowry's Method}

The total protein content was determined using modified Lowry's method. $0.5 \mathrm{~g}$ of sample was weighed. Ground in mortar and pestle with $5 \mathrm{ml}$ of $0.01 \mathrm{M}$ sodium phosphate buffer ( $\mathrm{pH} 7)$ and centrifuged at $8000 \mathrm{rpm}$ for $15 \mathrm{~min} .0 .1$ $\mathrm{ml}$ of supernatant was made up to $1 \mathrm{ml}$ with distilled water and mixed with $5 \mathrm{ml}$ alkaline copper reagent. It was allowed to stand for $10 \mathrm{~min}$ at room temperature followed by addition of $0.6 \mathrm{ml}$ Folin-Ciocalteau reagent (1:1 dilution) and was incubated for $30 \mathrm{~min}$ in the dark at room temperature. The absorbance was then measured at 660 $\mathrm{nm}$. Bovine Serum Albumin (BSA) was used as a reference standard for plotting calibration curve. The total protein content was determined from the linear equation of a standard curve prepared with $\mathrm{BSA}^{19}$. 


\section{Estimation of Total Carbohydrate By Anthrone Method Sample Extraction}

$10 \mathrm{mg}$ of the fresh sample was macerated with 6 drops of $0.2 \mathrm{~N}$ sulphuric acid and refluxed for $30 \mathrm{~min}$ in a flask. The mixture was then cooled and neutralized with a pinch sodium carbonate. The mixture was then made up to 50 $\mathrm{ml}$ with $0.2 \mathrm{~N}$ sulphuric acid and the contents were then centrifuged. The supernatant was then collected and used for the estimation of the amount of total carbohydrates present in the sample.

\section{Estimation of Total Carbohydrates}

0.2 to $1.0 \mathrm{ml}$ aliquots of standard glucose solution $1 \mathrm{mg} / \mathrm{ml}$ was utilized. $1 \mathrm{ml}$ of the sample solution was used for estimation. The volume in each of the tubes was made up to $1.0 \mathrm{ml}$ with distilled water. A blank test tube was prepared with $1 \mathrm{ml}$ distilled water. $4 \mathrm{ml}$ of anthrone reagent was added to each of the tubes following which the tubes were kept in a boiling water bath for $10 \mathrm{~min}$. The contents of each tube were mixed well and the absorbance was read at $630 \mathrm{~nm}$ against a blank. The readings were noted and a standard curve was plotted to determine the total carbohydrate content in the samples ${ }^{20}$.

\section{Estimation of Fat Content}

$5 \mathrm{~g}$ of food sample is taken. To this, $50 \mathrm{ml}$ of chloroformethanol mixture $(25 \mathrm{ml}: 25 \mathrm{ml})$ is added. It is then homogenized well and filtered through a fat free filter paper (Whatmanns no.1). The filtrate is collected in a separating funnel. The filtrate is then mixed with $2 \mathrm{ml}$ of physiological saline and the mixture is shaken well and kept undisturbed overnight. From the formed organic and inorganic layer, the organic layer is drained into a preweighed container. The container with the organic layer is left exposed to air overnight in order to evaporate the ethanol-chloroform mixture. The container is then kept in the oven. The difference between the weight of the empty container and the one with the sample is noted.

\section{Assessment of Glycemic Index}

The in-vitro method for evaluating starch digestion based on proteolysis, followed by incubation with pancreatic alpha-amylase. This method allows the calculation of a hydrolysis index (HI) which is the indicative of the food's glycemic index. $2 \mathrm{~g}$ of sample was ground in a mortar and pestle with $20 \mathrm{ml}$ of a $0.1 \mathrm{M}$ potassium phosphate buffer solution ( $\mathrm{pH}$ 6.9) kept at $37^{\circ} \mathrm{C}$ was added. After grinding, the samples were homogenized with a homogenizer at a constant speed and rinsed with an additional $20 \mathrm{ml}$ buffer solution. The $\mathrm{pH}$ of the samples was decreased to $\mathrm{pH} 2.5$ with ortho phosphoric acid, after which $1 \mathrm{ml}$ of pepsin enzyme (Sigma-Aldrich) was added. The samples were placed in a $37^{\circ} \mathrm{C}$ stirring water bath for 1 hour to stimulate the time that food would be churned in the human stomach. Each sample was then buffered back to $\mathrm{pH} 6.8$ with $\mathrm{KOH}$ and $2 \mathrm{ml}$ alpha amylase enzyme (Sigma-Aldrich) was added. The entire contents of the flask were then transferred into dialysis tube. The tube was closed and placed in beaker containing $500 \mathrm{ml}$ buffer solution and incubated at $37^{\circ} \mathrm{C}$ for three hours. Then the samples were extracted every 30 minutes. Aliquots of the dialysates were analyzed for reducing sugar by $3^{\prime} 5^{\prime}$ dinitrosalicylic acid (DNS) method.

The values were plotted on a graph and the area under the concentration-over-time curve (AUC) was determined ${ }^{1}$.

\section{$\mathrm{HI}=$ AUC of tested food/AUC of standard $* 100$}

\section{RESULT AND DISCUSSION}

\section{Estimation of Ash Content}

Table 1: Comparison of ash content of rice, millets and legume varieties represented as \%.

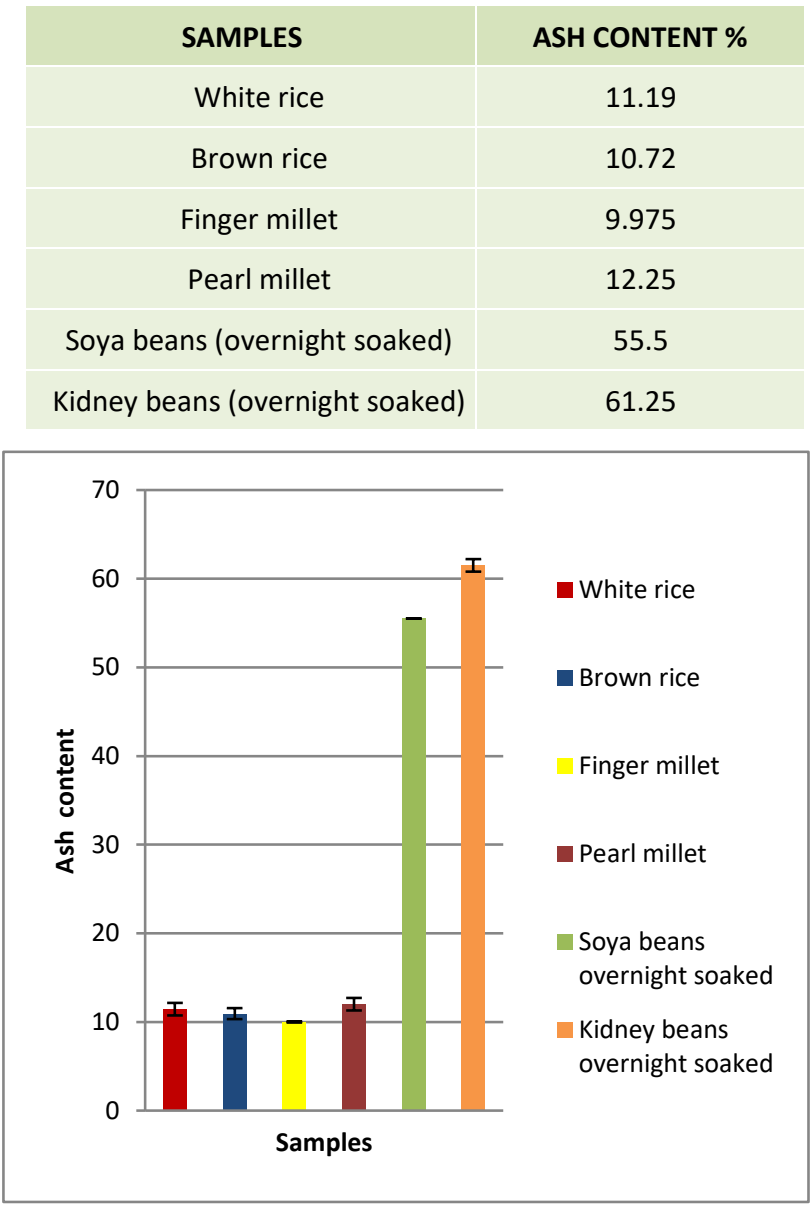

Figure 1: Comparison of ash content of rice, millets and legume varieties

Ash content of rice, millet and legumes were estimated using AOAC, 1984. Figure 1 and Table 1 illustrates the changes in the ash content. On determining the ash content of all the samples the highest ash content was observed in kidney beans that is $61.25 \%$ and lowest value was observed in the case of finger millet that is $9.975 \%$. Ash rich diet is the principal cause of reduction in blood glucose level so the diabetic patients can include kidney beans in their diet. 


\section{Estimation of Moisture Content}

Table 2: Comparison of moisture content of rice, millets and legume varieties represented as \%

\begin{tabular}{|c|c|}
\hline SAMPLES & MOISTURE CONTENT \% \\
\hline White rice & 9 \\
\hline Brown rice & 8 \\
\hline Finger millet & 8.5 \\
\hline Pearl millet & 9 \\
\hline Soya beans (overnight soaked) & 54.6 \\
\hline Kidney beans (overnight soaked) & 42.25 \\
\hline
\end{tabular}

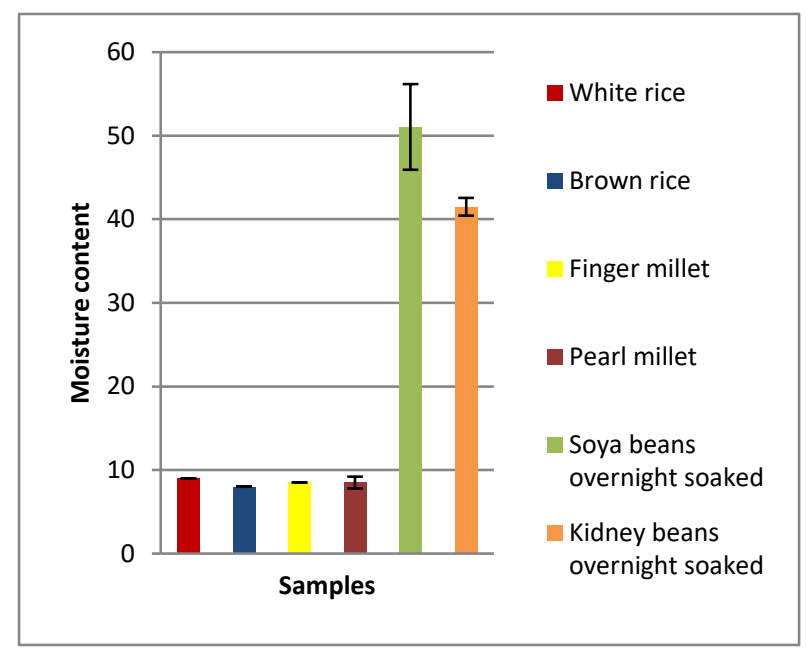

Figure 2: comparison of moisture content of rice, millets and legume varieties

Moisture content of the rice, millet, legumes was estimated according to the AOAC, 1984. Figure 2 and Table 2 illustrates the changes in the moisture content. On determining the moisture content for all the samples, it has been showed that the highest moisture content is corresponds to soya beans that is $54.6 \%$ and lowest value is corresponds to brown rice that is $8 \%$. Water removes large amount of sugar and ketones from our body when the individual is having more blood glucose level and kidney cannot process it. Therefore, moisture content is an important for type 1 diabetes, it is crucial to remove excess ketones from blood stream and reduce dehydration when blood sugars are high. Hence legumes are the best for diabetic patients.

\section{Estimation of Fibre Content}

Table 3: Comparison of fibre content of rice, millets and legume varieties represented as $\mathrm{g} / 100 \mathrm{~g}$

\begin{tabular}{|c|c|}
\hline SAMPLES & FIBRE CONTENT \% \\
\hline White rice & 0.14 \\
\hline Brown rice & 1.04 \\
\hline Finger millet & 1.20 \\
\hline Pearl millet & 1.48 \\
\hline Soya beans(overnight soaked) & 1.68 \\
\hline Kidney beans(overnight soaked) & 1.81 \\
\hline
\end{tabular}

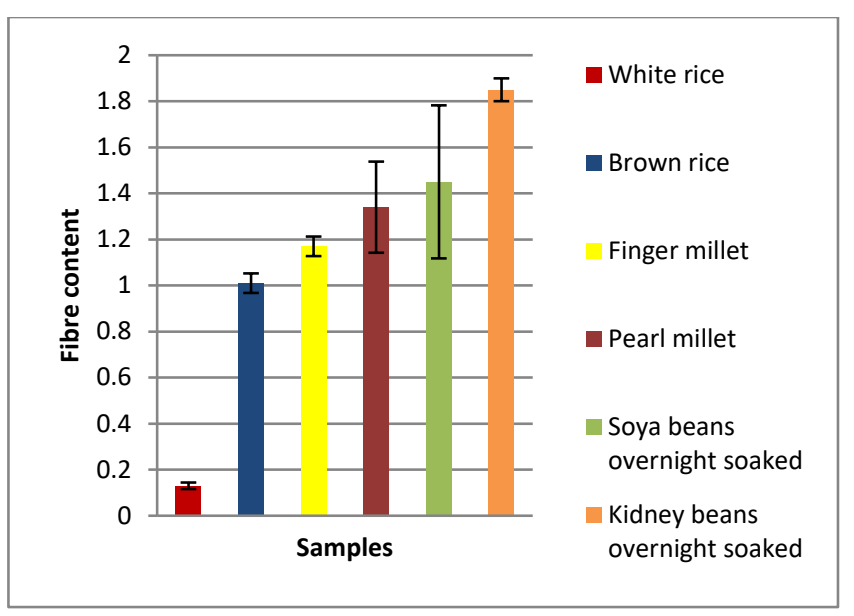

Fibre 3: Comparison of fibre content of rice, millets and legume varieties

Figure 3 and Table 3 illustrates that highest fibre content was observed in kidney beans that is $5.6 \%$ and lowest value was observed in the case of white rice which is 0.14 $\%$. From our experiment it has been showed that kidney beans has the highest amount of fibre content as it contains alpha galactosides, starch and pectin. And white rice has the lowest fibre content. Because fibre help lower the blood cholesterol level and improve blood glucose control if eaten in large amount and also keeps digestive tract working well

\section{Estimation of Fat Content}

Table 4: Comparison of fat content of rice, millets and legume varieties represented as $\mathrm{g} / 100 \mathrm{~g}$.

\begin{tabular}{|c|c|}
\hline SAMPLES & FAT CONTENT \% \\
\hline White rice & 1 \\
\hline Brown rice & 4.8 \\
\hline Finger millet & 1.8 \\
\hline Pearl millet & 6.8 \\
\hline Soya beans(overnight soaked) & 6.6 \\
\hline Kidney beans(overnight soaked) & 2 \\
\hline
\end{tabular}

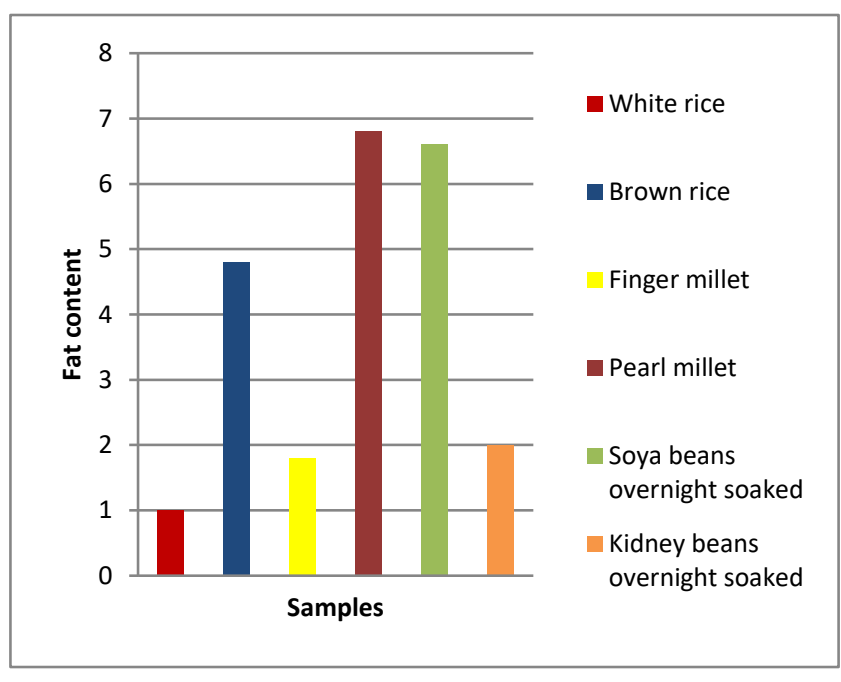

Figure 4: Comparison of fat content of rice, millets and legume varieties 
Figure 4 and Table 4 illustrates the changes in the fat content. On determining the fat content of all the above samples, the highest fat content was found in the case of pearl millet that is $6.8 \%$. And the lowest value of fat was observed in the case of white rice that is $1 \%$. Rice contains very low amount of fat whereas pearl millet and soya beans showed more amount of fat. Pearl millet is a good source of energy and the food value is higher than other types of cereals. Legumes contain about $5 \%$ of fat as an energy.

\section{Estimation of Protein Content}

Table 5: Comparison of protein content of rice, millets and legume varieties

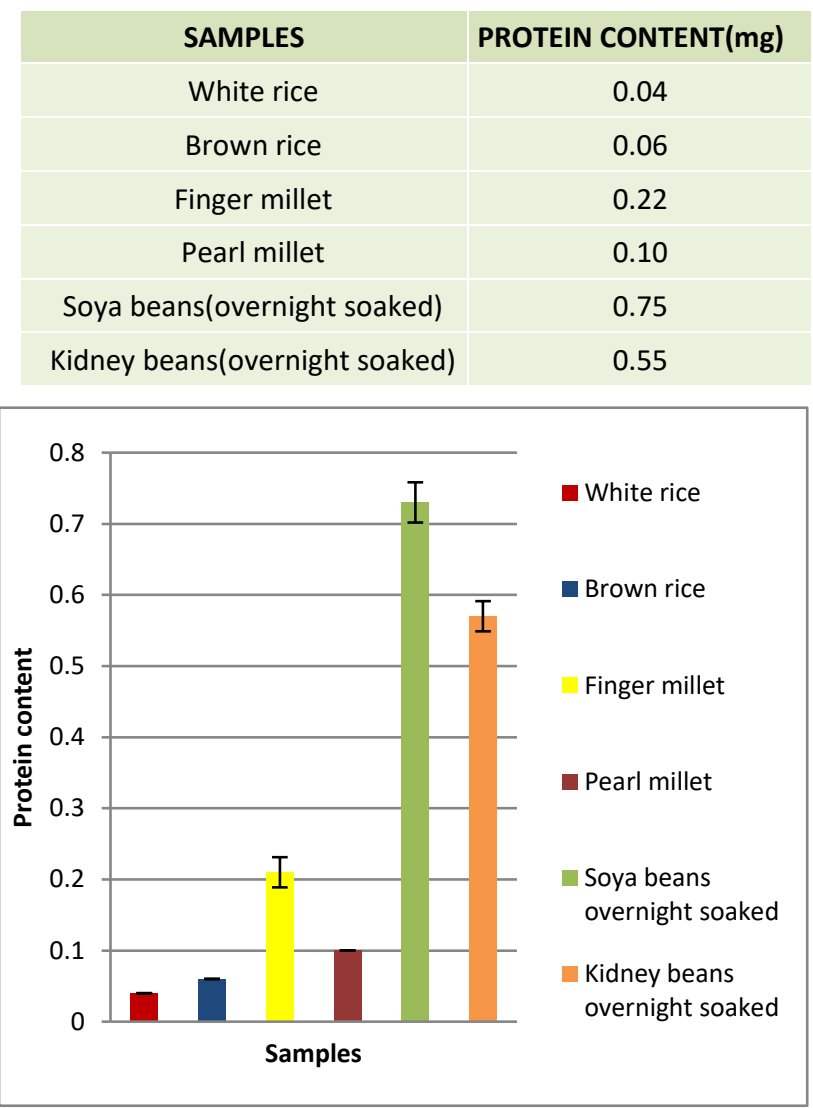

Figure 5: Comparison of protein content of rice, millets and legume varieties

Figure 5 and Table 5 illustrates the changes in the protein content. On determining the protein content in all the samples, the highest quantity of protein was observed in the case of soya bean that is $0.75 \mathrm{mg}$ and low amount of protein was observed in the case if white rice that is 0.04 $\mathrm{mg}$. In comparison between both the rice, brown rice has more protein than white rice. Soya bean are the principal source of protein. Approximately 1 cup of boiled soya beans can give $29 \mathrm{~g}$ of protein.

\section{Estimation of Carbohydrate Content}

Figure 6 and table 6 illustrates changes in the carbohydrate content. On determining the carbohydrate content of all the samples, the highest amount of carbohydrate was found in finger millet which is $0.11 \mathrm{mg}$ and low amount was found in soya bean that is $0.02 \mathrm{mg}$ and brown rice which is $0.02 \mathrm{mg}$. Carbohydrate is very important parameter in maintaining the blood glucose level because carbohydrate gets converted into the glucose and can manage sugar level. Hence diet followed by the people with diabetes tend to focus either on the quantity of carbohydrate intake or the speed at which carbohydrate are absorbed by the body.

Table 6: Comparison of carbohydrate content of rice, millets and legume varieties.

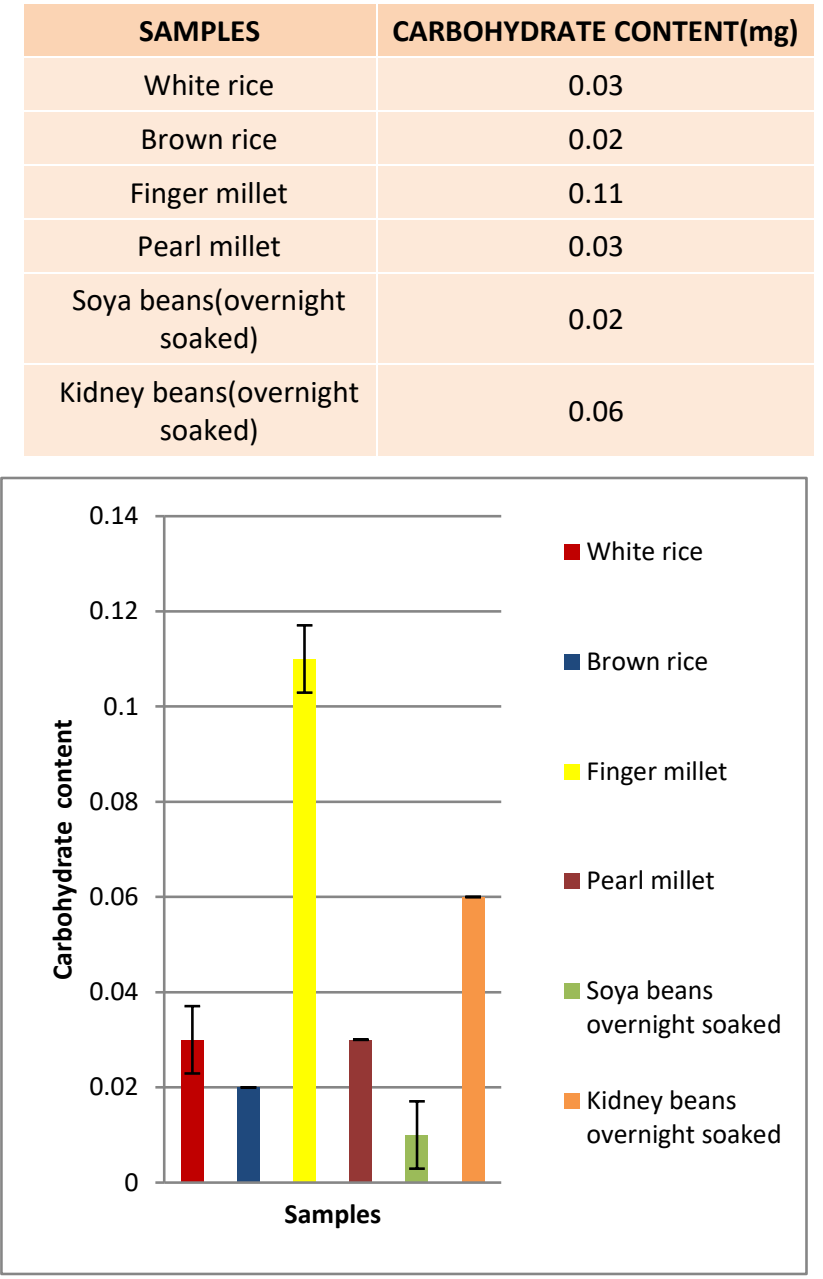

Figure 6: Comparison of carbohydrate content of rice, millets and legume varieties.

\section{Estimation Of Glycemic Index}

Table 7: Comparison of glycemic index of rice, millets and legume varieties.

\begin{tabular}{|c|c|}
\hline SAMPLES & GLYCEMIC INDEX \\
\hline White rice & 41.1 \\
\hline Brown rice & 40.2 \\
\hline Finger millet & 28.8 \\
\hline Pearl millet & 52.225 \\
\hline Soya beans(overnight soaked) & 22.72 \\
\hline Kidney beans(overnight soaked) & 15.6 \\
\hline
\end{tabular}




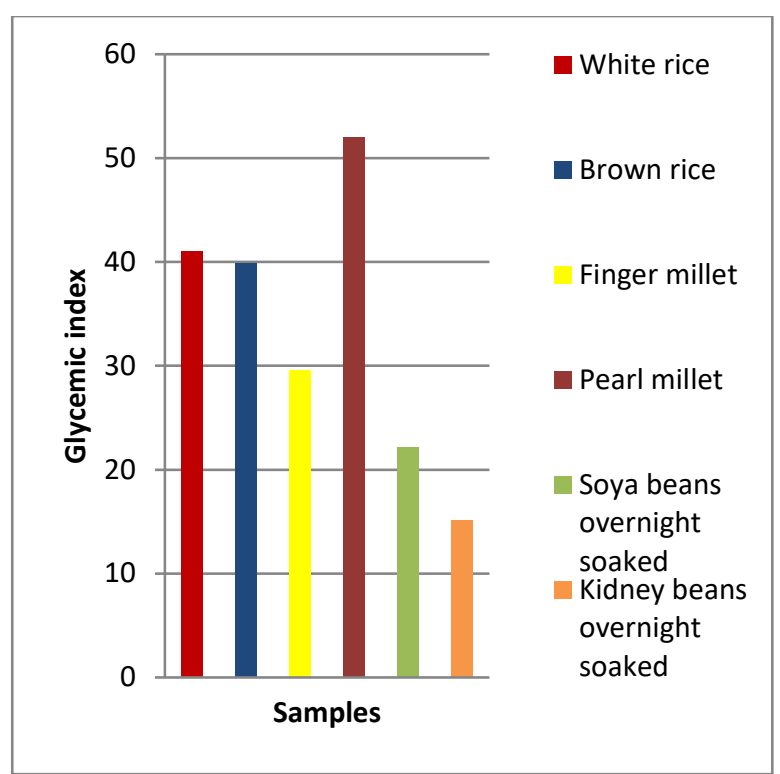

Figure 7: Comparison of glycemic index of rice, millets and legume varieties.

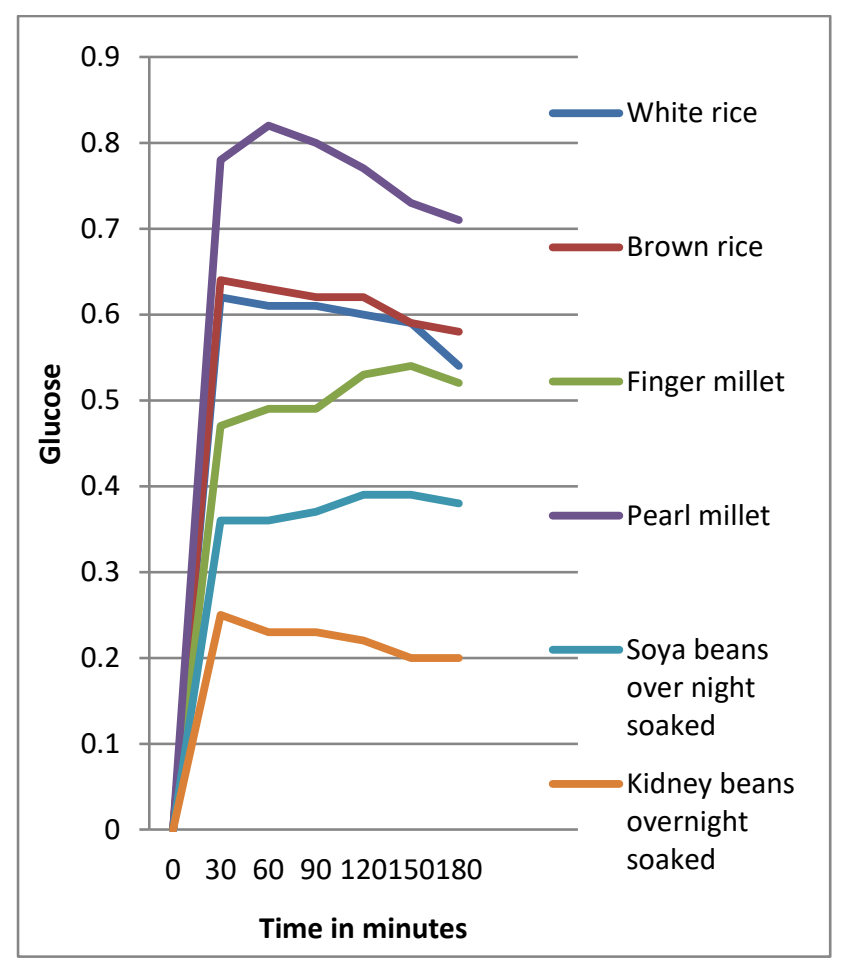

Figure 8: Glycemic response of rice, millets and legumes

In managing the diets of diabetic patients, the major objective is to reduce or prevent hypoglycemia episodes in insulin treated diabetes. Fat and fibre tend to lower the glycemic index of food. The glycemic index value is significantly lower in case of pearl millet and more in the case of kidney beans. In people with diabetes, the glycemic index value of a food is additionally affected by a person blood glucose level. Meal planning with the glycemic index involves choosing foods that have a low or medium glycemic index. If eating a food with high glycemic index, you can combine it with low glycemic index foods to help balance the meal.
Acknowledgement: We thank our institution and management for providing us the required facility and faculty, for their constant support.

\section{REFERENCES}

1. Goñi I, Garcia-Alonso A, Saura-Calixto F. A starch hydrolysis procedure to estimate glycemic index. Nutrition Research. 1997; 17(3): 427-437.

2. Björck I, Liljeberg H, Östman E. Low glycaemic-index foods. British Journal of Nutrition. 2000; 83(S1): S149-S155.

3. Jenkins D, Wolever $T$, Taylor R, Ghafari H, Jenkins A, Barker $\mathrm{H}$ et al. Rate of digestion of foods and postprandial glycaemia in normal and diabetic subjects. BMJ. 1980; 281(6232): 14-17.

4. Thompson L, Yoon J, Jenkins D, Wolever T, Jenkins A. Relationship between polyphenol intake and blood glucose response of normal and diabetic individuals. The American Journal of Clinical Nutrition. 1984; 39(5): 745751.

5. Yoon, J., Thompson, L. and Jenkins, D., 1983. The effect of phytic acid on in vitro rate of starch digestibility and blood glucose response. The American Journal of Clinical Nutrition, 38(6), pp.835-842.

6. Vadivel V, Janardhanan K. Nutritional and Antinutritional Characteristics of Seven South Indian Wild Legumes. Plant Foods for Human Nutrition. 2005; 60(2): 69-75.

7. Brekke H, Ludvigsson J. Daily vegetable intake during pregnancy negatively associated to islet autoimmunity in the offspring-The ABIS study. Pediatric Diabetes. 2009; 11(4): 244-250.

8. Miller G, Prakash A, Decker E. Whole-grain foods in health and disease American Association of Cereal Chemists. 2002.

9. Wet JMJ. Eleusine coracana. In: Brink M, Belay G, editors. Wageningen, Netherlands; 2006.

10. Dida MMD, M K. Finger millet. Chittarajan, K, Genome Mapping and Molecular Breeding in Plants, SpringerVerlag. 2006; 1: 333-344.

11. Bhatt A, Singh V, Shrotria PK, Baskheti DC. Coarse Grains of Uttaranchal: Ensuring sustainable Food and Nutritional Security. Indian Farmer's Digest. 2003; 34-38.

12. Jambunathan, R. and Subramanian, V. (1988) Grain quality and utilization of sorghum and pearl millet. In Biotechnology Workshop. Patancheru, ICRISAT. pp: 133139.

13. Henry C, Kaur B. Diet based management and treatment of diabetes. 2014.

14. Abdalla A, El Tinay A, Mohamed B, Abdalla A. Effect of traditional processes on phytate and mineral content of pearl millet. Food Chemistry. 1998; 63(1): 79-84.

15. FAO (1995) Sorghum and Millets in human nutrition. FAO, Rome.

16. Ejeta $G$, Hassen $M$, Mertz E. In vitro digestibility and amino acid composition of pearl millet (Pennisetum typhoides) and other cereals. Proceedings of the National Academy of Sciences. 1987; 84(17): 6016-6019. 
17. Bishnoi S. Effect of domestic processing and cooking methods on nutritional values of peas (Pisum sativum. [Hisar, India]: Haryana Agricultural University; 1992.

18. AOAC, Williams SW. Standard Official Methods of Analysis of the Association of Analytical Chemists. Washington. 1984; DC: 121.
19. Lowry O, Rosebrough N, Farr A, Randall R. PROTEIN MEASUREMENT WITH THE FOLIN PHENOL REAGENT. Journal of Biological Chemistry. 1951; 193(1): 265-275.

20. Miller G. Use of Dinitrosalicylic Acid Reagent for Determination of Reducing Sugar. Analytical Chemistry. 1959; 31(3): 426-428.

Source of Support: The author(s) received no financial support for the research, authorship, and/or publication of this article.

Conflict of Interest: The author(s) declared no potential conflicts of interest with respect to the research, authorship, and/or publication of this article.

For any question relates to this article, please reach us at: editor@globalresearchonline.net

New manuscripts for publication can be submitted at: submit@globalresearchonline.net and submit_ijpsrr@rediffmail.com 